\title{
O PROBLEMA DA ANÁliSE EM PESQUiSA CARTOGRÁFICA
}

\author{
Letícia Maria Renault de Barros ${ }^{I \star}$ Maria Elizabeth Barros de Barros ${ }^{I I} \star \star$ \\ ${ }^{I}$ Universidade Federal Fluminense, Niterói, RJ - Brasil

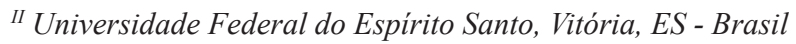

\section{RESUMO}

Este artigo aborda o papel da análise em uma pesquisa de abordagem cartográfica. Ao equivocar a noção de "dado", entendemos que a análise em cartografia leva a uma redefinição das fronteiras entre subjetividade $e$ objetividade. A análise em cartografia está afinada com outras abordagens de pesquisa e intervenção, assumindo diferentes procedimentos que permitem a análise de implicação na pesquisa e, por conseguinte, a análise da participação. Como efeito da análise, há o reposicionamento do lugar dos participantes na pesquisa. A análise em cartografia permite, ao longo de toda a realização da pesquisa, o acesso a uma objetividade que, em lugar de fixar um sentido unívoco, tende a proliferar sentidos. A cartografia afirma tal paradoxo por meio de uma atitude analítica, agente de singularização.

Palavras-chave: metodologia; análise de dados; pesquisa-intervenção.

\section{THE PROBLEM OF ANALYSIS IN CARTOGRAPHIC RESEARCH}

\begin{abstract}
This article discusses the role of analysis in a study of cartographic approach. When we question the notion of "data" we mean that the analysis in cartography leads to a redefinition of the boundaries between subjectivity and objectivity. The mapping analysis is tuned to other research approaches and intervention, assuming different procedures that enable the analysis of implication in the research and therefore the analysis of the participation. As a result of the analysis, there is a repositioning of the place of the participants in the study. The mapping analysis allows, throughout the research, access to an objectivity that, instead of fixing unambiguously, tends to proliferate directions. Cartography supports this paradox through an analytic attitude, a singling agent.

Keywords: methodology, data analysis, intervention research.

\footnotetext{
^ Psicóloga. Possui mestrado em Psicologia pela Universidade Federal Fluminense. Doutoranda em Psicologia pela Universidade Federal Fluminense.

E-mail: lerenault@gmail.com doutorado em saúde pública pela ENSP/Fiocruz. Atualmente é professora titular da Universidade Federal do Espírito Santo. Endereço: Universidade Federal do Espírito Santo, Centro de Ciências Humanas e Naturais, Departamento de Psicologia. Av. Fernando Ferrari, s/n - Goiabeiras. Vitoria, ES - Brasil. CEP: 29060900.

E-mail: betebarros@uol.com.br
}

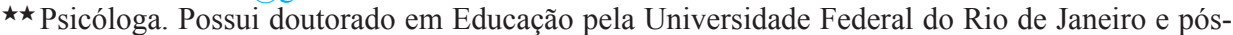


Tradicionalmente, diz-se que um processo de pesquisa lida com dados. A coleta de dados e, em seguida, sua análise, são tidas como atribuições do processo de pesquisa e etapas a serem seguidas na produção de conhecimento. Mas qual o sentido de "dado" para a cartografia? Considerando que cartografia é um método de pesquisa-intervenção (PASSOS; BENEVIDES DE BARROS, 2009) e está ligada ao acompanhamento de processos (POZZANA; KASTRUP, 2009) e à dissolução do ponto de vista do observador (PASSOS; EIRADO, 2009), torna-se imprescindível esclarecer em que sentido se compreende um dado cartográfico. Ao promover intervenção, o processo de pesquisa faz emergir realidades que não estavam "dadas", à espera de uma observação. Além disso, há uma temporalidade na emergência dessas realidades, isto é, há um processo cujo término não coincide necessariamente com a conclusão do cronograma da pesquisa. Por fim, o processo de pesquisa implica em um rearranjo das fronteiras inicialmente estabelecidas entre sujeito e objeto: a direção da cartografia é a de dissolver o ponto de vista para o qual surge, de maneira correlata, uma realidade supostamente dada em si mesma e dotada de substancialidade.

Mas se, por um lado a cartografia não lida com "dados" no sentido mais tradicional do termo, ela também não pode se esquivar do fato de que ela gera efeitos. Como nos indica Latour (2007), o processo de pesquisa instaura no mundo um "antes" e um "depois". Para a cartografia, que se reconhece implicada nesse processo de produção de realidade, a tarefa de análise em pesquisa ganha relevo. Ao compreender o conhecimento como um ato criador, como indicavam Maturana e Varela (2005), a cartografia se compromete de maneira significativa com a análise do processo de pesquisa a ser empreendido, ainda que tal análise não se exerça sobre dados, isto é, sobre uma objetividade tida como independente da própria pesquisa.

Para compreender do que trata a análise em cartografia, é preciso, então, especificar a que ela se volta, tomando a noção de dado em outro sentido. A "análise de dados" é, na tradição representacional de pesquisa, o momento em que se procura acessar e resguardar a objetividade. Subjacente a este procedimento de análise, há uma concepção de objetividade. As modulações que a cartografia imprime em tal concepção definem alguns dos aspectos principais relativos ao tema da análise.

Para a cartografia, a objetividade não é algo a ser protegido de supostas investidas subjetivas. Tal compreensão subentenderia que objetividade e subjetividade são essencialmente separadas e que há, de direito, uma única fronteira entre elas. Essa não é, de modo algum, a compreensão da cartografia. $O$ entendimento habitual acerca da objetividade (e da subjetividade) está baseado nas experiências cotidianas nas quais sujeito e objeto nos surgem como separados um do outro. A cartografia, no entanto, volta-se à dimensão genética dessas experiências, acompanhando o estabelecimento dessas fronteiras entre sujeito e objeto, diferentes a cada vez. Ao fazê-lo, a cartografia lança luz sobre processos em que sujeito e objeto definem-se mutuamente, um em função do outro. Portanto, a experiência comporta tanto subjetividade quanto objetividade, de modo que, para a cartografia, esses termos não têm o mesmo sentido que em outros campos de conhecimento. 
Em outros procedimentos de pesquisa, que tomam a cognição por seu caráter de representação, os dados informam algo sobre o objeto estudado; a objetividade do conhecimento produzido está na sua correspondência com esse objeto. Mas, para a cartografia, que aborda não apenas os objetos, mas seu processo de constituição, onde está a objetividade? Como ela se orienta em direção ao que ela se propõe a investigar?

Para compreender o problema da análise, é preciso compreender também o que se analisa, isto é, o que são "dados" para a cartografia. Um determinado objeto, nesse modo de fazer pesquisa, torna-se o ponto de partida para acessar a experiência. É preciso atentar para o fato de que a noção de experiência que guia a pesquisa não a institui como um novo objeto (EIRADO et al., 2010). Em relação à experiência, não há como manter a atitude típica que mantemos em frente de objetos, baseada na crença de que eles existem independentemente de nossa relação com eles. $\mathrm{O}$ acesso à experiência modula todo o procedimento de pesquisa, porque faz aparecer uma dimensão participativa na constituição dos objetos. Sendo assim, também a análise deve caminhar na direção da participação.

A análise, assim, pode partir de um objeto com contornos precisos, mas alcança, progressivamente, um conjunto de múltiplas relações que lhe permite surgir como tal. Participam de sua emergência muitos outros aspectos, que, a princípio, trataríamos como the sendo externos. O procedimento analítico vai permitir o aparecimento das condições de emergência do objeto, possibilitando à pesquisa comportar a heterogeneidade e a heterogênese.

O que move a análise em cartografia, portanto, são problemas. É a um problema que ela se volta e são também problemas o seu resultado. É preciso lembrar as indicações de Bergson (1974), de que toda "solução" é coextensiva a um modo de colocar o problema; o problema não é dado, ele depende da criação dos termos nos quais ele vai se apresentar. Analisar é, assim, um procedimento de multiplicação de sentidos e inaugurador de novos problemas.

Portanto, o que é incontroverso ou inequívoco não oferece, para a cartografia, nenhum privilégio na produção de conhecimento. Para a cartografia, os dados não se constituem como tais porque são passíveis de verificação ou de reprodução. O conhecimento a ser produzido e compartilhado pela pesquisa cartográfica abrange as zonas de ambiguidades, acolhendo a experiência sem desprezar nenhuma de suas faces, seja a da objetividade, seja a da subjetividade.

Se na base de um problema há invenção e heterogeneidade, sua análise em uma pesquisa supõe a aproximação das experiências vividas tanto pelo pesquisador quanto pelo participante. Esta atitude da pesquisa cartográfica em relação à análise está afinada com a atitude de outros procedimentos de pesquisa e intervenção, como a de algumas experiências na clínica ou na analise institucional, por exemplo. Lourau (2004) indica que o método analítico em pesquisa, na sua definição "clássica" visa explicar uma realidade complexa a partir da "decomposição de um todo em seus elementos", analisando a relação entre eles. A análise se efetiva a partir da decomposição de uma totalidade em elementos que a compõem. Segundo Lourau (2004), não se trata de interpretar ou construir um 
discurso explicativo, mas evidenciar elementos que compõem um conjunto. No caso das ciências humanas acrescenta-se a isso a ideia de interpretação como operação de deciframento. A análise transforma-se em hermenêutica, como ciência da interpretação do que está oculto (LOURAU, 2004).

Na pesquisa cartográfica toda análise é análise de implicação (RODRIGUES, 2012). Aqui se anuncia uma oposição radical às pretensões de neutralidade analítica do pesquisador, que já está implicado no campo de pesquisa. $\mathrm{O}$ método analítico consiste, então, em dar visibilidade às relações que constituem uma dada realidade, na qual o pesquisador se encontra enredado.

Tal manobra analítica visa dar visibilidade à dinâmica instituído-instituinte que constitui as instituições. Nessa dinâmica, se expressam manifestações de não conformidade com o instituído, o revelado, que são os analisadores. É o analisador que realiza a análise; ao pesquisador cabe a construção de analisadores. Analisar é evidenciar, por meio dos analisadores, o processo de produção histórica das instituições, desnaturalizando-as. A análise faz aparecer esse esquecimento, essa ignorância institucional instituída, esse silêncio sobre o que e como se institui dada realidade.

Assim, o objetivo da análise é "validar" o conceito de analisador. Todas as situações de análise-intervenção estão baseadas no manejo de analisadores construídos, atualizados com o objetivo de fazer emergir material analisável (LOURAU, 2004).

O pesquisador é o analista e não o analisador. O pesquisador-analista indica os efeitos dos analisadores que desencadeiam uma intervenção, entendendo que não basta reconhecer, legitimar ou exaltar a existência de analisadores, mas compreender que somente os analisadores o constituem como analista, que não pode se subtrair aos efeitos analisadores do dispositivo de intervenção.

Como diz Rodrigues (2012, p. 39), analisar pode constituir

palavra de desordem de invenção, de conexão, de transgressão. Implicantes e implicadas, pragmáticas ou processualidades, elas insistem em problematizar, na contracorrente dos sedentarismos analíticos 'solucionadores'. Cabe a nós, em modos de viver e pesquisar, evitar que se transformem em tranquilizantes (e perigosas) disciplinas.

Modos de análise surgem insurgindo-se contra qualquer palavra de ordem que decrete haver eterna e infinitamente uma ordem predeterminada.

Assim, o modo como a pesquisa se organiza altera o sentido da análise. Análise implica atitude. É ethos analítico. A análise se faz por problematização e tem dimensão participativa. Não basta, entretanto, "dar a palavra" aos sujeitos envolvidos, numa atitude formal, quase "jesuítica" (LOURAU, 2004). 
Essa postura analítica vai questionar a naturalidade dos objetos, dos sujeitos, dos saberes e do próprio processo de pesquisa, assim como as relações que constituem um território e sua pretensa homogeneidade. As forças que constituem as relações pesquisador e campo de pesquisa são privilegiadas, indicando-se a coemergência desses polos e colocando em discussão as práticas de poder-saber como produtoras de verdades consideradas universais e eternas.

Rompe-se, assim, com uma lógica da neutralidade em pesquisa, afirmando-a como intervenção. Inquire-se a gênese e o funcionamento das instituições que constituem sujeitos e objeto de pesquisa; criando-se possibilidade de emergência de outros modos de pensamento/ação, a pesquisa se faz criação. A realidade não é capturada como forma dada, tida como natural, mas tomada como forma a ser posta em análise.

Tal movimento de interrogação que a análise viabiliza se efetiva na constituição de um plano da pesquisa que indaga as demandas presentes no campo de intervenção e as forças e acontecimentos considerados estranhos ou silenciados por serem tidos como impeditivos de uma pesquisa bem-sucedida. Como afirma Rodrigues (2012), a análise, como análise de implicação, é generalizada e deriva na ideia de transversalidade, rompendo-se com a ilusão de totalidade fechada em pesquisa.

Diríamos, então, que a análise se aproxima de uma dimensão clínica que privilegia os processos criadores que possibilitam reposicionamento subjetivo. Essa dimensão clínica da análise indica, portanto, uma inseparabilidade análise-política. Nessa interface análise-clínica-política estamos afirmando que nesse processo nos encontramos com modos de produção de subjetivação, "modos de experimentação/construção e não mais interpretação da realidade, modos de criação de si e do mundo que não podem se realizar em sua função autopoiética, sem o risco constante da experiência de crise". (BENEVIDES DE BARROS; PASSOS, 2004). Arriscar-se numa experiência de crítica, de análise das formas instituídas nos compromete politicamente. Tal operação de análise implica a desestabilização das formas instituídas e acessa o plano de forças a partir do qual a realidade se constitui, devolvendo-a ao plano de sua produção, que é o plano coletivo, heterogêneo e heterogenético, que experimenta, incessantemente, diferenciação. E é aí que se efetiva a análise como experiência clínica, ou seja, como experimentação no plano coletivo das forças, que não se restringe ao domínio das pessoalidades.

Esse manejo da análise não se caracteriza pelo emprego forçoso de nenhum procedimento analítico específico. Ou seja, não é a utilização de um procedimento que vai definir a atitude analítica. Alguns procedimentos de análise, como contar o número de ocorrências de uma palavra ao longo de um texto, ${ }^{1}$ por exemplo, podem servir para controlar o viés subjetivo do pesquisador e procurar o sentido objetivo dos dados, em uma preocupação com a localização do sentido que é estranha à cartografia. Portanto, a atitude da análise não se confunde com um padrão fixo de procedimentos metodológicos, nem com o emprego de uma determinada sequência de etapas. Há, de fato, proximidade entre a atitude analítica presente em diferentes abordagens de pesquisa e intervenção, tais como a análise do discurso, a análise institucional, a própria cartografia e também algumas 
práticas clínicas. A escolha do procedimento vai-se definir por uma imersão na experiência da pesquisa e supõe que a análise de implicações já esteja em curso. Sendo assim, o que orienta o desenvolvimento da análise é o próprio problema, que passa por modulações ao longo do processo de pesquisa.

Se há algo de analítico na escolha inicial dos procedimentos a serem empregados é porque, em cartografia, não há como separar a análise das demais fases da pesquisa. Ela não é uma etapa a ser realizada apenas ao final do processo, na qual o material de campo poderia ser, enfim, compreendido. A atitude de análise acompanha todo o processo, permitindo que essa compreensão inicial passe por transformações. Por isso, em cartografia não há uma separação entre as fases de coleta e análise; tal atitude subentende também algum tipo de separação entre o objeto e o sujeito que o conhece. Como consequência de separar radicalmente a análise da dita "coleta" do material de campo, há a caracterização da análise como um procedimento de decomposição em relação ao sentido, isto é, como um meio de determinar onde se localiza o sentido obtido ao final do processo - se no mundo objetivo ou na subjetividade do pesquisador.

A atitude da cartografia, incluindo aí sua atitude analítica, caminha na direção inversa e busca reportar-se à gênese comum de sujeito e objeto. Por isso, quando nos referimos à relação com a pesquisa de campo na cartografia, é mais apropriado falar em cultivo do que em coleta (DEPRAZ; VARELA; VERMERS$\mathrm{CH}, 2003)$. A cartografia procura estabelecer outro ponto de partida, abrangendo também o plano coermergente da experiência, a partir do qual sujeito e objeto se constituem (MATURANA; VARELA, 2005; VARELA, 1988; VARELA; THOMPSON; ROSCH, 2003). Sendo assim, a cartografia lida com um aspecto da experiência que está aquém do representacional, tendo por direção remontar ao seu plano coemergente (PASSOS; BENEVIDES DE BARROS, 2009; PASSOS; EIRADO, 2009; ALVAREZ; PASSOS, 2009). Os critérios representacionais de análise, portanto, não lhe são suficientes.

Mas o que se analisa, então, em cartografia? Afirmamos que a cartografia gera efeitos e mantém um compromisso com a análise. No entanto, a análise pode prescindir de um vínculo com o tema da objetividade? Considerando a coemergência, afirmamos que os objetos não existem por si mesmos. A cartografia estaria, então, imersa num terreno inteiramente subjetivo, no qual haveria apenas produção, livre de quaisquer critérios ou referenciais para a análise?

Ora, abranger a coemergência não é o mesmo que decretar a ausência de objetividade. Em primeiro lugar, é preciso entender qual o sentido de objetividade: ela não necessariamente se define em contraposição a uma subjetividade constituída por representações. Ao contrário, o subjetivismo que concebe a experiência como propriedade de um sujeito essencialmente separado do mundo é apenas a outra face da objetividade dotada de substancialidade e independente da experiência. O trabalho de Whitehead (WAHL, 1932) pode contribuir para a compreensão de outro sentido para a objetividade, tendo-se em vista a coemergência. De acordo com Whitehead, definir objetividade e subjetividade em contraposição uma à outra corresponde a uma abstração em relação à própria 
experiência, que não nos oferece imediatamente uma separação entre os polos subjetivo e objetivo. É preciso fazer um juízo sobre a experiência para estabelecer uma fronteira entre o que nos aparece de fato - nossa percepção do mundo - e o que existiria para além desta aparência - a objetividade, a ser alcançada apenas por conjecturas. Ao realizarmos tal juízo, desconfiamos da experiência e pressupomos de antemão a existência de tal fronteira entre o aparente e o real. Hábitos cientificistas podem nos fazer "tomar o abstrato pelo concreto" (WHITEHEAD, 2006, p. 71) e a supor uma separação entre a matéria e a mente; tal suposição é fruto de construções lógicas, abstratas, mas habitualmente a tomamos como uma realidade concreta e a empregamos para organizar a pesquisa da verdade científica. No entanto, as abstrações não explicam a experiência, ao contrário, elas é que devem ser explicadas. Para Whitehead, a experiência mesma não se confunde com os juízos que fazemos sobre ela. Acessar a experiência corresponde a "tomar o dado como ele nos é dado, sem fazer uma divisão preliminar entre o aparente e o real [...]" (WAHL, 1932, p. 129).

A cartografia não é um subjetivismo, no sentido mais corriqueiro do termo, pois, para se conceber a subjetividade localizável em um sujeito como mais originária, é preciso já ter estabelecido de antemão um corte entre sujeito e objeto. Acompanhando Whitehead (1932, p. 131), nossa experiência concreta nos mostra que habitamos um mundo, "somos em meio a outras coisas que são igualmente". O mais concreto, portanto, é a própria experiência. Tomando-a como ponto de partida, não há nem um sujeito originário, produzindo realidades arbitrariamente, nem objetos a serem subjetivamente apreendidos, sob a forma de representações ou deturpações de dados existentes por si mesmos. Nesse sentido, J. Wahl (1932, p. 131) caracteriza a filosofia de Whitehead como "objetivista", uma vez que seu ponto de partida não estabelece distinções prévias entre subjetividade e objetividade, privilegiando um dos polos como mais originário. Negando a bifurcação da natureza, Whitehead restitui algo de subjetividade aos próprios acontecimentos.

Assim, considerando-se a coemergência, a experiência não pode ser apartada do mundo, como uma entidade cuja natureza seria essencialmente distinta dos objetos mesmos, supostamente não experienciais. A objetividade, aqui, é a da própria experiência em seu aspecto criador. Ao nos voltarmos ao plano pré-refletido da experiência (EIRADO et al., 2010), nos aproximamos da exploração de um domínio acerca do qual J. Wahl (1932, p. 161), seguindo Whitehead, afirma:

Deste domínio onde nós nos movemos agora, não se pode dizer que ele é subjetivo nem que ele é objetivo, ou, mais exatamente, subjetivo ao seu mais elevado ponto, ele nos revela isto que é objetivo ao mais elevado ponto [...]

Quais as indicações para análise que podemos depreender daí? Em seu apelo ao concreto, Whitehead nos chama a atenção para o fato de que não há como aproximar-se de uma experiência apenas por meio de um vocabulário genérico. Daí a importância de elementos demonstrativos simples, como "aqui" e 
"agora". Essa mesma atitude está na base de trabalhos como os empreendidos por V. Despret (2011), M. Foucault (2003a; 2003b) e, como veremos a seguir, serve de pista para a realização de pesquisas cartográficas.

\section{ObJetos, MÉTOdos e PROBLEMAS}

A questão da análise está em evidência no trabalho de V. Despret. Em seu estudo com os animais, Despret $(2010,2011)$ coloca-se na arriscada posição de receber as críticas comumente dirigidas à etologia, que seguem o argumento de Russell, ironicamente questionador: não é curioso que os animais frequentemente se comportem de modo a provar a teoria de quem os observa? Tal argumento coloca em dúvida a autenticidade do conhecimento em etologia - se as observações estão a serviço da teoria dos pesquisadores, não há qualquer objetividade em relação aos dados produzidos. $\mathrm{O}$ viés subjetivo do pesquisador seria, então, o responsável pelas características observadas nos animais - ou, poderíamos dizer, nos outros. Não seríamos capazes de ter nenhum grau de liberdade em relação ao nosso próprio ponto de vista, de modo que tudo o que observamos estaria sempre enviesado, seria sempre a "nossa" interpretação subjetiva. Ao formularmos o problema desse modo, esquecemos, no entanto, que não há "eu" sem o "outro". Pesquisador e animais estão imersos em uma mesma cultura, em um mesmo dispositivo de pesquisa, afetando-se mutuamente. Ao aprofundarmos o ponto de vista do pesquisador, vemos que ele não se sustenta isoladamente, o "outro" já está lá. Desse modo, as características "subjetivas" que encontramos no comportamento animal não são necessariamente uma ilusão ou um mal-entendido. Elas são parte da experiência a ser pesquisada, que comporta tanto subjetividade quanto objetividade, sem separação nem primazia entre esses aspectos da experiência.

Ao assumirmos como verdadeiras as críticas dirigidas à etologia, toda conclusão a respeito dos comportamentos dos animais nada diria sobre "os animais", o objeto pesquisado. Tais pesquisas seriam sempre auto-referidas, com resultados provenientes apenas das percepções subjetivas e teorias dos próprios pesquisadores. Despret, no entanto, realiza seu trabalho sem se esquivar desse risco. Graças à sua atitude de pesquisa, colocam-se outras questões analíticas, de modo que a autenticidade dos dados deixa de ser o único critério disponível para a análise. Em vez de se perguntar como o observador influencia o observado, Despret faz a pergunta inversa: como o observado influencia o observador? Por acreditarmos que esta questão tem uma resposta evidente, nunca a colocamos seriamente. Ao fazê-lo, Despret nos força a prestar atenção em nossa própria forma de articulação com o mundo e a nos vermos como instrumentos de sua negociação. Nesse caso, mais do que procurar deslocar o olhar do cientista sobre os animais, fazendo-o ver suas próprias limitações, Despret indica que é preciso, deixar-se afetar pelo campo.

A princípio, afirmar a inseparabilidade entre sujeito e objeto poderia tão somente nos levar a procurar "pôr em análise" o ponto de vista do pesquisador de campo, colocando em questão a autenticidade dos dados observados e fazendo a crítica do conhecimento produzido. As indicações de Despret, contudo, demonstram que ainda não há, aí, afirmação da coemergência: é preciso tornar-se 
disponível ao campo para, então, poder deparar com uma objetividade inegável. Ao acompanhar um etologista no campo, podemos, por exemplo, observar junto com ele que não há outra possibilidade de interpretação para um acontecimento, ou seja, podemos entender que a experiência que ele tem com os animais também pode ser nossa experiência. Para análise em uma pesquisa, é importante não esquecer a inseparabilidade entre os pontos de vista e manter a atenção desperta para o aspecto coemergente da experiência.

Ou seja, para analisar, foi preciso estar no campo. O conhecimento produzido tinha uma pertinência que não lhe seria acessível enquanto ela se situasse apenas no plano da crítica. Estar no campo provocava uma modificação mútua entre observador e observado, e qualquer descrição que passasse ao largo desta experiência simplesmente "não estava à altura do acontecimento". No entanto, o sentido de "estar no campo" não se restringe à presença física do pesquisador no campo, como se a noção de "estar presente" fosse uma questão meramente geográfica. Trata-se, antes, de uma questão relativa à atenção. É preciso estar atento ao que os animais nos respondem, é preciso não negligenciar os animais na análise do conhecimento produzido.

Isso significa, necessariamente, estar atento também às próprias perguntas: fizemos as perguntas que interessam? O interesse em uma pesquisa é mútuo, ele concerne tanto a pesquisadores quanto a pesquisados. Por isso se pode afirmar que a pesquisa é intervenção: porque ela gera articulação. Ao se articularem em um dispositivo de pesquisa, os participantes geram um reposicionamento de fronteiras. Tal articulação é, simultaneamente, a participação na pesquisa e a descrição desse reposicionamento. Ou seja, articular-se é participar ativamente na produção de conhecimento: a pesquisa é tanto mais articulada quanto mais participativa. A objetividade na pesquisa, assim, não está situada em uma anterioridade em relação à própria pesquisa, em um suposto domínio isento de subjetividade. A objetividade, aqui, é a da própria articulação sujeito-objeto, que podem surgir, um para o outro, como interessantes ou como irrelevantes. É que recolocar o objeto em nossas análises, situando-o localmente e recusando o anonimato pretensamente generalizante que costumamos atribuir aos participantes das pesquisas em psicologia, é também um modo de recolocar o sujeito - não há objeto sem sujeito. Acessar a experiência em uma pesquisa nos coloca, assim, diante da fronteira cambiante ente objetividade e subjetividade; é preciso estar disponível para ambas para acolher a experiência.

É nesse sentido que Despret (2011) afirma que as pesquisas com animais podem nos ajudar a descobrir coisas sobre nós mesmos: não há "nós mesmos" separado dos objetos que interrogamos. É preciso, como indicava Whitehead, reportarmo-nos ao concreto e situar a pesquisa em termos locais, interrogando-nos acerca das boas condições de sua realização. A objetividade que está em jogo é a da experiência com o dispositivo de pesquisa, no qual observador e observado se articulam de maneira singular. Ao consultarmos esta objetividade, somos levados a analisar a pesquisa e a reformular nossas questões, a fim de torná-las mais interessantes e mais pertinentes. Apenas em recurso a esta objetividade podemos analisar o quão boas são as nossas perguntas de pesquisa. 
Como esta objetividade comparece em uma pesquisa de abordagem cartográfica? Uma pesquisa realizada sobre a produção de saúde e doença de professores de uma escola pública no município da Serra/ES (Secretaria de Estado da Educação - SEDU) levou-nos a enfrentar o desafio de criar condições de participação dos docentes que trabalhavam num estabelecimento da rede pública de educação da cidade. O desafio foi o de garantir o protagonismo dos diferentes sujeitos envolvidos no processo investigativo: pesquisadores da universidade, docentes e direção da escola, e, visando uma análise da atividade escolar. Esta operação pretendia tornar inseparáveis a atividade de análise e a atividade analisada, fazendo do processo de pesquisa uma investigação com o trabalhador.

Habitando esse horizonte ético-político, foi utilizada como instrumento a produção videográfica e que se efetivou em discussão junto com os professores da escola, quando foi feito um roteiro de imagens como prescrição para a atividade videográfica. Nesse quadro metodológico, a tarefa apresentada aos sujeitos consistia em elucidar para o outro e para si mesmo as questões que surgem durante o desenvolvimento das atividades com as imagens e, em seguida, a escolha das situações que constituiriam o objeto da análise. Essas decisões foram elas mesmas objeto de um primeiro trabalho, quando as cenas foram selecionadas em função de critérios elaborados com os docentes da SEDU. Esse coletivo, que forma um "meio associado" (SIMONDON, 1969) à pesquisa, permaneceu como interlocutor privilegiado da equipe da universidade. Foi com ele que no final foram retomados e retrabalhados os materiais filmados. A análise da atividade seguiu, portanto, três fases: de início, um longo trabalho de "concepção partilhada" das situações a serem analisadas; em seguida, uma concentração na produção de documentos videografados e a terceira fase se fez com uma volta ao "meio associado" por meio de um trabalho de co-análise da atividade docente. Nessa última fase, produziu-se o que se pode chamar de filtragem da experiência profissional posta em discussão em termos de situações rigorosamente delimitadas. O grupo de referência assumia, assim, uma função de planejamento, execução, acompanhamento e avaliação, constituindo-se num meio de preparação para a atividade de captação das imagens. Esse momento desenvolve a dimensão coletiva da pesquisa, instaurando-a como suporte para a videogravação que foi feita por um professor escolhido no grupo. Sendo assim, vão-se borrando os limites da autoria, de maneira que se possa perceber o trabalho como obra coletiva. No trajeto as interferências constantes dos próprios professores, cuja atividade tornava-se foco de atenção, foram cruciais para as montagens e modulações do dispositivo dialógico por videografia. Isso possibilitou fraturar a dicotomização entre sujeito e objeto de pesquisa. Ao promover a intervenção, fazia-se emergir realidades que não estavam "dadas", à espera de uma observação. O processo engendrado na escola implicou em um rearranjo das fronteiras inicialmente estabelecidas entre pesquisadores da Universidade Federal do Espírito Santo (UFES) e docentes da escola: a direção era outra, dissolver o ponto de vista segundo o qual surge numa pesquisa uma realidade supostamente dada em si mesma e dotada de substancialidade.

Pretendia-se, dessa forma, responder às constantes inquietações dos professores relativas às pesquisas realizadas "sobre" eles. Em geral, eram pesquisas que trabalhavam almejando coletar dados, a fim de obter informações, do trabalho do 
professor ; a devolutiva resume-se, na maioria dos casos, à produção de publicação científica, e os sujeitos-objetos de pesquisa são considerados mera fonte de matéria-prima informante dos dados a serem analisados pelo pesquisador. Esta série de críticas aos protocolos tácitos de pesquisa era tecida pelos próprios docentes, que questionavam acerca do processo de produção de conhecimento acadêmico. $\mathrm{O}$ trabalho de análise, estendendo-se em três diferentes momentos, foi, aqui, a oportunidade para que os próprios docentes escolhessem o que era interessante para ser pesquisado. Esse trabalho de escolha não se dá sobre um conteúdo neutro, independente de um observador; a própria seleção do material é já produtora de um mundo, é já analítica. $\mathrm{O}$ alvo do trabalho de análise não era apenas o conteúdo do que foi filmado. O próprio ato de filmar compunha também o processo de análise, pois foi incluído na pesquisa como um gesto ao mesmo tempo portador de sentido e como algo capaz de produzir deslocamentos de ponto de vista. Nesse caso, o que é "objetivo" para essa pesquisa, o que é passível de análise, não estava "dado". A análise se deu por meio da relação que se foi estabelecendo entre todos os participantes da pesquisa-docentes, alunos, pesquisadores e demais "associados".

Foi essa a direção de análise, forjada pelo encontro conflitivo entre professores e pesquisadores da UFES, de forma a não encontrar os docentes como meros sujeitos-objetos de pesquisa, a partir dos quais colheríamos dados, mas como analistas do trabalho que desenvolvem. Analistas imersos no cotidiano laboral, investidos dos saberes da experiência. A análise, portanto, não era responsabilidade exclusiva dos pesquisadores. Uma vez convidados a participar da produção de conhecimento, os professores também se tornam analistas e, com isso, uma nova realidade pode emergir. Durante o processo de pesquisa, os professores puderam manter outra relação com o sentido de sua atividade. A elaboração e divulgação da pesquisa, por sua vez, torna possível ampliar as redes de associação nas quais a pesquisa estava baseada, permitindo que ela se torne interessante e viva para outros que não estiverem presentes (geograficamente) no campo de intervenção.

A aposta metodológica implementada considerou que, em pesquisa-intervenção, é preciso, em vez de cumprir tão somente as formalidades de apresentação de um contrato de participação na pesquisa e assinatura do termo de consentimento livre e esclarecido, criar um processo de contratação. Processo esse que permitisse a constituição de um "grupo sujeito" da atividade da pesquisa, um plano comum que, sem pressupor indistinções, afirma diferenciações pelo fazer junto, que se constrói por controvérsias, por combates, lutas que se fazem entre nós, por nós.

Tal manobra metodológica vislumbrava a construção de um plano comum, o que se efetivou por meio do acompanhamento dos docentes nos percursos tecidos no/com o cotidiano da escola, acompanhá-los na gestão do processo de trabalho que ali se atualizava e no processo de produção de imagens do trabalho feita por eles próprios. Definiu-se, então, conjuntamente, quem filmaria e quais momentos deveriam ser registrados. Sendo assim, podemos dizer que a pesquisa, para alcançar seu objetivo, para acessar a experiência do labor, para realizar a análise, precisava compartilhar. As imagens gravadas em vídeo dispararam um rico debate sobre a atividade docente. Assim, com a câmera nas mãos, o professor indicado produziu um filme a partir de cenas definidas pelo coletivo de docentes. 
A edição do filme foi feita com a participação do professor/videasta, que definia com os pesquisadores da UFES a estrutura do filme a ser apresentado para uma confrontação com os colegas de trabalho. O próprio processo de filmar, de pensar e escolher o quê filmar ou não, já o coloca como analista do seu trabalho e com ele os dados são cultivados. A análise está presente em todo o processo de pesquisa e não apenas em sua conclusão.

$\mathrm{Na}$ análise da pesquisa, que tinha a preocupação de colocar em coanálise a atividade docente, a noção de dado passa a ter outro sentido. A preocupação não era a de resguardar uma objetividade, buscando produzir um conhecimento objetivo sobre o trabalho docente, dotado de imparcialidade e assegurado por seu vínculo com prescrições sobre como trabalhar, independentemente do próprio processo de pesquisa. Não se teria, assim, "dados" no sentido mais tradicional do termo, mas a pesquisa gerava efeitos. O compromisso era com a maneira como a análise do processo de pesquisa se efetivava. Tal análise não era exercida sobre dados com uma objetividade independente da própria pesquisa, como se se estivesse frente a uma atividade docente independente do ato de pesquisar, dados que se prestariam ao controle e à previsão. Não é necessário recorrer a algo fora da experiência para que se produza um conhecimento acessível a todos. O objetivo é obter um conhecimento comum, passível de ser compartilhado, acessando-se a experiência. Vislumbrava-se um aspecto da experiência do labor docente que está aquém do representacional, tendo por direção remontar ao seu plano co-emergente, sendo a objetividade a própria experiência do labor em seu aspecto criador.

O que se coloca como tarefa da análise, portanto, é permitir constantemente que a própria pesquisa seja interrogada. Acessar a objetividade da experiência, em seu plano co-emergente, permite reformular as perguntas e tornar os observados efetivamente co-participantes da pesquisa. De acordo com Latour (2007), as contribuições à epistemologia trazidas por essas investigações seguem na direção de maximizar a recalcitrância dos pesquisados, isto é, de procurar garantir a capacidade dos participantes da pesquisa de se objetarem. Tal capacidade de objeção é importante, pois a análise "na" pesquisa é inseparável da análise "da" pesquisa. Não é possível analisar o mundo sem que essa análise envolva também quem o analisa: a análise supõe a participação da multiplicidade que se encontra articulada em um contexto e em um problema de pesquisa.

Mas, para maximizar a capacidade de objeção, não basta estar atento ao próprio dispositivo. Os questionamentos acerca da pertinência da pesquisa provêm, muitas vezes, de direções inesperadas e díspares. Achar a boa pergunta, tornar a pesquisa interessante, não é uma tarefa a ser desempenhada de maneira arbitrária pelo pesquisador. Não é ele quem decide o que é interessante, do mesmo modo que não é propriamente o participante quem o determina. A pergunta acerca do interesse nos conduz a um domínio de sentido em que pesquisador e participante são mais as criaturas do que os criadores. Para acessar esse domínio, é preciso ampliar a atenção. 
A atitude de pesquisa de M. Foucault pode vir a esclarecer esse ponto. Seu trabalho implica um procedimento de análise que, em lugar de procurar definir uma causa ou um determinante histórico, faz intervir uma multiplicidade de processos constituintes, que são heterogêneos entre si e que, em uma abordagem mais tradicional da história, poderiam ser tidos como "externos" ao que se quer pesquisar. Ao voltar-se à história, Foucault procede de maneira diversa de historiadores em busca de exatidão (FOUCAULT, 2003a). Ao fazê-lo, o autor recusa também a distinção que pretende colocar historiadores de um lado e filósofos do outro - os primeiros, do lado da "poeira", isto é, da precisão dos pequenos e inúmeros fatos históricos, e os segundos, do lado da "nuvem", da imprecisão de grandes sistemas, vagos e sem concretude. Em lugar disso, Foucault trabalha para estabelecer outro tipo de distinção, entre a "análise de um problema e o estudo de um período" (FOUCAULT, 2003b, p. 324). Para os que se propõem a estudar um período histórico, a fidelidade à cronologia e o tratamento exaustivo dos materiais de pesquisa são essenciais. Segundo esta atitude de pesquisa, o procedimento de Foucault é arbitrário e vago: ele seleciona documentos e não se prende a datas. Mas Foucault afirma não estar estudando períodos, isto é, dados ou objetos históricos; ele estuda problemas, é neles que encontra a objetividade. Portanto, são os problemas que guiam a análise de Foucault. Suas regras de pesquisa são: "escolha do material em função dos dados de um problema; focalização da análise sobre os elementos suscetíveis de resolvê-lo; estabelecimento das relações que permitem essa solução" (FOUCAULT, 2003b, p. 326).

Há em Foucault uma atenção ao caráter singular dos problemas. Ele procura situá-los, compreendê-los de maneira local, tomando os objetos a partir dos problemas, e não o inverso. O objeto estudado emerge do problema - é no sentido do problema que se encontram as condições de análise. Daí a diferença entre as duas atitudes de pesquisa apresentadas por Foucault (2003b, p. 327):

Uma, que consiste em se dar um objeto e em tentar resolver os problemas que ele pode causar. A outra, que consiste em tratar um problema e em determinar, a partir daí, o domínio de objeto que é preciso percorrer para resolvê-lo.

Os vídeos feitos pelos professores não são, assim, a resposta a um problema; eles são a própria constituição de um problema que não estava dado anteriormente.

Os critérios de análise em uma pesquisa de problemas não podem ser, assim, os da fidedignidade. Não há a expectativa de se atingir a completude de um objeto ou dado do real. Foucault (2003c, p. 339) denomina o procedimento de análise empregado por ele de "acontecimentalização". Sua análise visa a "fazer surgir uma "singularidade" (FOUCAULT, 2003c, p. 339), recusando a evidência e o caráter de necessidade de que se revestem os temas pesquisados quando são tidos como dados, tomando aqui o termo em seu sentido mais comum, presente na maior parte das pesquisas científicas. Os vídeos na pesquisa com os docentes instauram uma realidade, não buscam retratar um dado. Isso não quer dizer que 
eles não tenham pertinência; eles procuram permitir um reposicionamento perante questões que surgiam como óbvias em relação à atividade de docência. Tais efeitos de reposicionamento nos servem de índice de sua pertinência.

É assim que, na pesquisa cartográfica, não se espera tecer uma explicação para o acontecimento, determinando-lhe as causas históricas. Ao contrário, como Foucault (2003c, p. 339), procura-se "reencontrar as conexões, os encontros, os apoios, os bloqueios, os jogos de força etc. que, em um dado momento, formaram o que, em seguida, funcionará como evidência, universalidade, necessidade". Tal procedimento, em vez de tender para uma unificação de sentido e determinação de uma causa, reencontra uma multiplicidade que desaparecera na constituição do "dado histórico".

Portanto, para a cartografia há um paradoxo da análise em pesquisa, que é o de acessar uma objetividade que tende à proliferação de sentidos, em vez de restringir um sentido único. A experiência que está na base da pesquisa - e, portanto, da análise - é criadora. É isso que a noção de co-emergência nos recorda. Não há objeto que anteceda as objeções, nem um fato histórico descolado de um problema. Busca-se "estar presente" em seu campo, desde que consideremos como presença esse estado de atenção em que se torna possível restituir ao dado seu caráter de acontecimento.

No caso da análise na intervenção com os docentes, a pesquisa cartográfica permite que a atividade de ensinar seja vista por outros ângulos, que o professor, ao filmar, se reposicione diante do que lhe surgia como um dado e, ao deslocar-se em relação ao seu ponto de vista mais imediato, possa recolocar os problemas, renovando, para si próprio e para os outros, o interesse em sua atividade.

A análise de uma pesquisa pode ajudar a devolver a multiplicidade de sentidos que está na gênese do dado. Com isso, a pesquisa pode ampliar sua abertura ao que, a princípio, ela não era capaz de incluir. Podemos aqui retomar a advertência de Latour (2007), de que há um "antes" e um "depois" da pesquisa: é preciso que a pesquisa esteja atenta aos seus efeitos e disponível às objeções. A análise da pesquisa deve nos informar a respeito do quão interessantes foram os efeitos produzidos e quais foram as articulações engendradas. Ao trabalharmos em pesquisa considerando a co-emergência de si e do mundo intrínseca ao ato de conhecer (MATURANA; VARELA, 2005), não é possível analisar algo sem que a análise recaia também sobre quem analisa - a pesquisa.

Diferentes pesquisas - como as de Foucault e Despret -, se veem às voltas com trabalhos bastante específicos: as práticas de encarceramento (FOUCAULT, 2003a; 2003b; 2003c), a dança dos pássaros Babblers (DESPRET, 2010), ou, ainda, a análise da experiência do labor (UFES). Evidenciar tais especificidades contidas nesses trabalhos é a condição para produzir um conhecimento comum, que tenha um sentido passível de ser compartilhado, afinal, replicabilidade não é compartilhamento. Quando pensamos em replicabilidade da pesquisa, não há acontecimentalização. $\mathrm{O}$ que se repete é apenas o procedimento. Já quando há compartilhamento, compartilha-se o método de acesso ao singular, pela via da atitude e do campo problemático. Ou seja, repete-se a atitude, o campo proble- 
mático e o procedimento. A preocupação é outra: indicar aos outros pesquisadores qual o sentido da pesquisa realizada, mostrando como esse sentido pode ser compartilhado. Ao se falar em replicabilidade, entende-se que há um conjunto de regras fixas de realização de uma técnica, que garantem a comunidade. Há dificuldade em continuar a conversa quando há apenas a constatação de uma dada situação. Não tomar o sentido como "dado" não é privar-se de uma objetividade. Contudo, a condição de compartilhamento também não está no uso de procedimentos socialmente estabelecidos, tidos como padrão de objetividade. Os procedimentos metodológicos utilizados, muitas vezes, estiveram a serviço dos problemas colocados. Portanto, não é a fidelidade a procedimentos de coleta ou de análise de dados que garante algum acesso à objetividade, o que coloca em xeque a suposição de que os procedimentos metodológicos são externos ao cerne das pesquisas. O método não é independente do sentido dos problemas pesquisados. O tema da análise, assim, nos indica que a possibilidade de acessar um plano comum depende de uma atenção à singularidade.

\section{CONSIDERAÇões FINAIS}

A análise em cartografia, portanto, não prescinde de uma discussão acerca da objetividade. O sentido de "dado", aqui, precisa levar em conta essa discussão. Se para a análise é preciso considerar o acontecimento, a constituição de um objeto como tal, na cartografia não pode ser senão como processo. A análise de processos depende de um recuo em relação ao caráter "dado" do sentido em uma pesquisa, como se ele fosse evidente ou necessário. A análise de processos coloca-se ao lado da experiência, o que é bem diferente de afirmar que ela se apoia uma evidência. Ora, afirmar que a experiência nos põe diante do que é evidente apenas denunciaria a irrelevância da própria análise.

Mas, como vimos ao longo do texto, a objetividade da experiência nem sempre nos é óbvia ou instantaneamente acessível. Depraz, Varela e Vermersch (2006) nos recordam que nossa experiência não é transparente para nós mesmos, há dimensões da experiência que não são conscientemente reconhecidas em nosso modo habitual de estar no mundo. É preciso dispor de método (a suspensão) e de técnicas de atenção específicas para acessar essa experiência.

Ora, se isto se dá com nossas vivências mais cotidianas, como a percepção e a lembrança, o mesmo ocorre nos procedimentos de pesquisa. Nem sempre acessamos a objetividade dos nossos problemas de pesquisa, isto é, seu caráter de acontecimento. Muitas vezes partimos de objetos que nos aparecem como dados, com um caráter de evidência que oculta o acontecimento no qual eles se apoiam. É aí que a tarefa da análise pode ajudar, permitindo um recuo em relação ao sentido que nos surge como dado.

Esse recuo, no entanto, não representa, como na estratégia representacional de pesquisa, um afastamento da experiência. Ao contrário, é preciso um grau crescente de contato com a experiência para que a evidência se dilua. 
Ao contrário de algumas perspectivas que supõem a análise como um momento específico da pesquisa (que pode se dar depois da coleta ou em simultaneidade a ela), a análise em cartografia é, também ela, processual, e inerente a todos os procedimentos de pesquisa. Em alguns métodos de análise, como na análise de conteúdo (BARDIN, 2010), por exemplo, deve-se num primeiro momento, proceder à abertura e à proliferação de sentidos (por meio de atividades exploratórias e não estruturadas) e, num momento posterior, devem ser estabelecidos os critérios de interpretação e de formulação dos resultados. Esse primeiro momento é tido como uma fase de pré-análise, embora dela dependa todo o restante do procedimento analítico. Para a cartografia, ao contrário, a abertura à multiplicidade de sentidos não pode ser temporalmente localizada na pesquisa. Ela se dá ao longo de todo o processo; sustentar a atitude de abertura é, inclusive, uma das tarefas principais da análise na pesquisa.

É interessante observar, contudo, que mesmo para a análise de conteúdo, é importante haver uma fase de análise em que os procedimentos ainda não estão muito bem definidos, em que é preciso testar e experimentar diferentes técnicas. Esse fato pode ser mais bem compreendido se lembrarmos que os procedimentos, por si só, não garantem a objetividade da análise. É preciso uma conexão com os problemas de pesquisa e não há um padrão metodológico que determine tal conexão. Para a escolha dos procedimentos de análise é preciso acessar o sentido dos problemas.

Por isso, a cartografia não pode se privar, de antemão, do emprego de quaisquer procedimentos. As técnicas descritas pela análise de conteúdo (BARDIN, 2010), tais como contar o número de ocorrências de uma palavra em um texto para retomar o exemplo dado no início do artigo - podem ser uma ferramenta útil para escapar à evidência de um sentido único. De fato, o leitor/analista pode estar de tal forma aderido a seu próprio ponto de vista que um procedimento como esse pode ajudá-lo a acessar outros sentidos e a permitir um descentramento, na direção da dissolução do ponto de vista do observador (PASSOS; EIRADO, 2009). Desse modo, colocar em análise o "viés subjetivo do pesquisador" pode ser importante, dependendo dos problemas com os quais a pesquisa vai lidar. No entanto, tal operação tem um valor prático, e não metafísico; não necessariamente ele será útil em todos os casos, nem indica que, em todos os problemas de pesquisa, há uma "subjetividade" que contamina e ilude.

Embora diversos, os procedimentos de análise empregados articulam-se segundo uma atitude comum. Tal atitude é o que define a análise em cartografia. Analisar é, de fato, sustentar um ethos analítico específico, permitindo que a pesquisa se volte para si mesma e se interrogue acerca da implicação e da participação, levando à problematização e ao reposicionamento do lugar dos participantes. Daí o paradoxo da análise, o de constituir-se ao mesmo tempo como um acesso à objetividade $\mathrm{e}$ como um procedimento de proliferação de sentidos e de singularização.

\section{Nota}

${ }^{1}$ Trata-se de um procedimento comumente utilizado na Análise de Conteúdo (BARDIN, 2010). 


\section{REFERÊNCIAS}

ALVAREZ, J.; PASSOS, E. Cartografar é habitar um território existencial. In: PASSOS, E.; KASTRUP, V.; ESCÓSSIA, L. da (Org.). Pistas do método da cartografia: pesquisa intervenção e produção de subjetividade. Porto Alegre: Sulina, 2009. p. 131-149.

BARDIN, L. Análise de conteúdo. Lisboa: Ed. 70, 2010.

BENEVIDES DE BARROS, R.; PASSOS, E. Clínica, política e as modulações do capitalismo. In: Revista Lugar Comum, Rio de Janeiro, n. 19-20, p. 159-171, jan.-jun. 2004.

BERGSON, H. O pensamento e o movente (Introdução). In: Os pensadores: Bergson e Bachelard. São Paulo: Abril Cultural, 1974.

DEPRAZ, N.; VARELA, F.; VERMERSCH, P. On becoming aware: a pragmatic of experiencing. Philadelphia-Amsterdam: Benjamin, 2003.

DEPRAZ, N.; VARELA, F.; VERMERSCH, P.; A redução à prova da experiência. Arquivos Brasileiros de Psicologia, Rio de Janeiro, v. 58, n. 1, 2006. Disponível em: <http://pepsic.bvsalud.org/scielo.php?pid=S180952672006000100008\&script=sci arttext $>$. Acesso em: 03 maio 2013.

DESPRET, V. Ethology between Empathy, Standpoint and Perspectivism: the case of the Arabian babblers. 2010. Disponível em: <http://www.vincianedespret. be/2010/04/ethology-between-empathy-standpoint-and-perspectivism-the-caseof-the-arabian-babblers/\#more->. Acesso: 13 jan. 2013.

DESPRET, V. O que as ciências da etologia e da primatologia nos ensinam sobre as práticas científicas? Fractal: Revista de Psicologia, Niterói, v. 23, n. 1, p. 5972, jan./abr. 2011.

EIRADO, A. et al. Estratégias de pesquisa no estudo da cognição: o caso das falsas lembranças. Psicologia \& Sociedade, v. 22, n. 1, p. 84-94, 2010.

FOUCAULT, M. Vigiar e Punir. Petrópolis: Vozes, $2003 a$.

FOUCAUlT, M. A Poeira e a Nuvem (1980). In: MOTTA, M. B. (Org.). Estratégia, Poder-Saber. Rio de Janeiro: Forense Universitária, 2003b. Coleção Ditos \& Escritos, v. 4, p. 323-334.

FOUCAULT, M. Mesa-redonda em 20 de maio de 1978. In: MOTTA, M. B. (Org.). Estratégia, Poder-Saber. Rio de Janeiro: Forense Universitária, 2003c. Coleção Ditos \& Escritos, v. 4, p. 334-351. 
LOURAU, R. Analista em tempo integral. ALTOÉ, S. (Org.). São Paulo: Hucitec, 2004

LATOUR, B. Como falar do corpo? A dimensão normativa dos estudos em ciência. In: NUNES, J. A.; ROQUE, R. (Org.). Objetos impuros: experiências em estudos sociais da ciência. Porto: Afrontamento, 2007. p. 40-61.

MATURANA, H.; VARElA, F. A Árvore do Conhecimento. São Paulo: Palas Athena, 2005.

PASSOS, E.; BENEVIDES DE BARROS, R. A cartografia como método de pesquisa-intervenção. In: PASSOS, E.; KASTRUP, V.; ESCÓSSIA, L. (Org.). Pistas do método da cartografia: pesquisa intervenção e produção de subjetividade. Porto Alegre: Sulina, 2009. p. 17-31.

PASSOS, E.; EIRADO, A. Cartografia como dissolução do ponto de vista do observador. In: PASSOS, E.; KASTRUP, V.; ESCÓSSIA, L. (Org.). Pistas do método da cartografia: pesquisa intervenção e produção de subjetividade. Porto Alegre: Sulina, 2009. p. 109-130.

POZZANA, L.; KASTRUP, V. Cartografar é acompanhar processos. In. PASSOS, E.; KASTRUP, V.; ESCÓSSIA, L. da (Org.). Pistas do método da cartografia: pesquisa intervenção e produção de subjetividade. Porto Alegre: Sulina, 2009. p. $52-75$.

RODRIGUES, H. C. de B. Analisar. In: FONSECA, T.; NASCIMENTO, L.; MARASCHIN, C. (Org.). Pesquisar na diferença. Porto Alegre: Sulina, 2012.

SIMONDON, G. L'Individuation psychique et collective. Paris: Aubier, 1969.

VARELA, F. Conhecer: as ciências cognitivas tendências e perspectivas. Lisboa: Instituto Piaget, 1988.

VARELA, F.; THOMPSON, E.; ROSCH, E. A mente incorporada: ciências cognitivas e experiência humana. Porto Alegre: ARTMED, 2003.

WAHL, J. Vers le Concret. Paris: Vrin, 1932.

WHITEHEAD, A. N. A ciência e o mundo moderno. São Paulo: Paulus, 2006.

Recebido em: 05 de maio de 2013

Aceito em: 17 de julho de 2013 